\title{
Stability Analysis and Control Measures of Large-Span Open-Off Cut with Argillaceous Cemented Sandstone Layered Roof
}

\author{
Wenxiang Zheng $\mathbb{D}^{1},{ }^{1}$ Yujie Guo $\mathbb{D}^{1},{ }^{1}$ Guojun $\mathrm{Zhi}^{2}$ Xiankai Bao, ${ }^{1}$ Ming Sun, ${ }^{1}$ Ruiping Ren, ${ }^{2}$ \\ Zhijun Duan, ${ }^{1}$ and Zhendong Gao ${ }^{1}$ \\ ${ }^{1}$ Inner Mongolia University of Science and Technology, Baotou 014010, Inner Mongolia, China \\ ${ }^{2}$ Wanli No. 1 Coal Mine of Shenhua Baotou Energy Group Co., Ltd., Ordos 017000, Inner Mongolia, China \\ Correspondence should be addressed to Yujie Guo; guo1115@foxmail.com
}

Received 25 April 2021; Accepted 31 May 2021; Published 14 June 2021

Academic Editor: Qiuhong Wu

Copyright (c) 2021 Wenxiang Zheng et al. This is an open access article distributed under the Creative Commons Attribution License, which permits unrestricted use, distribution, and reproduction in any medium, provided the original work is properly cited.

\begin{abstract}
This paper is based on the condition where layered argillaceous cemented sandstone as an engineering background is met by the No. 207 fully mechanized working face open-off cut (Wanli No. 1 Coal Mine). Through mechanical theory analysis and field practice, the engineering safety problem of the large-span argillaceous cemented sandstone layered open-off cut roof supporting structure was analyzed. The roof caving arch height of the open-off cut roadway in 207 working face was obtained based on the mechanical mechanism of instability and caving of the layered surrounding rock mass roof. The anchor cable suspension and bearing stability of the open-off cut roof were analyzed in terms of the layered beam structure model. Meanwhile, combining with conditions, reasonable and effective support countermeasures and key parameters are proposed for such open-off cut roadway and enhance the actual supporting engineering on-site. These research results could provide engineering reference for an open-off cut roadway with composite roof conditions featured to weak cementation and weak interlayer.
\end{abstract}

\section{Introduction}

With the gradual improvement of the mine modernization level in our country and considering the development requirements of mine safety, the development trend of largescale working face equipment has become further obvious. In this regard, the cross section of the corresponding working face open-off cut roadway also keeps enlarging, for which the open-off cut span increases from $5.5 \mathrm{~m}$ to $7 \mathrm{~m} \sim 10 \mathrm{~m}$ gradually. The argillaceous cemented sandstone layered roof has the characteristics of low shear strength and poor bond force. By improper and late supporting measures, interlaminar dislocation separation is simply induced, leading to catastrophes. Many domestic and international scholars have made unremitting exploration and innovation on the stability of large-span roadway, composite roof, working face open-off cut roadway, and so on. They achieved numerous outstanding achievements with different characteristics [1-8].
Li et al. $[9,10]$ applied theoretical analysis, numerical calculation, and site measurement to research the deformation, displacement, and failure characteristics of largespan open-off cut. The type of surrounding rock and support parameters were identified, and the combined support was designed with a left-hand rebar bolt, metal net, metal beam, and anchor. Zhang et al. [11, 12] performed the support optimization design of a large section roadway through three-dimensional numerical simulation by using the FLAC3D. It was based on the engineering practice of the large section roadway in Zhaozhuang Mine, including a composite roof of mudstone and sandy mudstone and the shale floor. They optimized the row spacing between the bolt and put forward an anchor-anchor cable integrated supporting parameters optimization program to match the large section of the composite roof. Zhang et al. [13] performed a comprehensive in situ investigation on the failure process of a gob-side entry suffering dynamic stress induced by an extra-thick coal seam mining. Yu et al. [14] considered the 
problems of roadways with a compound roof, such as the occurrence of instability in the roof strata, ease of separation of the layer caving, difficulty of maintenance, and poor safety. In the present work, we established a mechanical calculation model of a roadway with a compound roof using the elastic mechanics' theory. Expressions of the separation layer and instability limit load of the compound roof were derived, and the calculation and verification were performed in combination with the actual conditions. Zheng et al. [15-18] used the superposition beam structure model to analyze the effect of the stress and deformation of the roadway roof and floor. They revealed the main factors affecting the stress and deformation of the composite roof and floor. With the deepening of the research on the surrounding rock control of the roadway, the anchor cable active support is extensively used in the large-span roadway support. The supporting design schemes have been proposed, such as bolt mesh cable composite support, bolt cable coordination support, and anchor cable center symmetrical support [19-24].

The development process of surrounding rock stability has been summarized and analyzed along with control measures of large-span roadway, composite roof, and working face open-off cut roadway. Hence, there are many places worth learning and using as a reference. However, due to the surrounding rock properties and the complexity of the geological environment, there is no unified solution to the problem of roadway stability. Thus, economic and effective prevention measures must be put forward based on specific conditions. Hence, this paper deals with the field analysis to reveal the mechanical failure characteristics of argillaceous cemented sandstone roofs. Through the stability mechanical analysis of large-span cutoff, the roadway with argillaceous cemented sandstone roof, the roof falling arch height, and mechanical stability criteria of cable suspension bearing of open-off cut roadway are obtained. Thus, integrating with the field conditions, the effective and reasonable supporting countermeasures and key parameters are put forward for such an open-off cut roadway. This research can provide technological and scientific support for domestic mine development and mining. It has a certain practical engineering application value.

\section{Stress and Failure Characteristics of the Large-Span Open-Off Cut Roof with Argillaceous Cemented Sandstone}

2.1. General Situation of the Engineering. As for 207 fully mechanized working faces of Wanli No. 1 Mine, the 31 upper coal seam (the buried depth is about $110 \mathrm{~m}$ ) is the main seam for mining, with an average coal thickness of $3.5 \mathrm{~m}, 0-8^{\circ}$ coal seam inclination angle, and 1 to 2 layers of gangue. The rectangular cross-section $(7600 \mathrm{~mm} \times 3500 \mathrm{~mm})$ of the 207 open-off cut roadway is dug along the floor. The roof is the fine siltstone featured with argillaceous cementation and poor stability. It is a soft and semihard rock stratum and easy to prone to roof instability. The floor is made of siltstone and fine sandstone, which are of argillaceous cementation.
2.2. Macroscopic Analysis of In Situ Deformation and Failure of the Large-Span Open-Off Cut Roof with Argillaceous Cemented Sandstone. Through the field investigation, it was found that the roof of the 207 open-off cut roadway is argillaceous cemented sandstone. This leads to low shear strength, poor adhesion between layers, and interlaminar dislocation and separation. The bearing stability of the surrounding rock of the sandstone roof is affected by the argillaceous cementation. The bending deformation of the surrounding rock of the cut roadway is obvious. The span of 207 cut roadway is largely limiting the effect of active support of argillaceous cemented sandstone roof.

\section{Mechanical Stability Analysis of Large-Span Open-Off Cut with Argillaceous Cemented Sandstone Layered Roof}

3.1. Mechanical Mechanism of Instability and Caving of Layered Rock Mass Roof Surrounding. The horizontal layered rock mass is considered the research object. When excavating the roadway in a horizontally stratified rock mass, there are different stress modes of rock stratum and the law of stress transfer between surrounding rock layers compared to the roadways with homogeneous surrounding rock conditions. Hence, the deformation law and failure form are also different from those of the roadway with the homogeneous surrounding rock.

To assess the medium stability of layered rock mass in the roadway, the mechanical model of the roof under layered rock mass is established, considering the following assumptions:

(1) The layered caving roof of rectangular roadway in the horizontal layered rock mass is simplified into a cantilevered rock superimposed beam model for analysis.

(2) The top of the layered rock mass on the left side of the rectangular roadway is studied since the rock properties of the left and right sides of the rectangular roadway are axisymmetric with the vertical axis of the roadway.

(3) Since the axial length of the roadway is much larger than the size of the cross section, there is the problem of plane stress and strain for the mechanical analysis of the surrounding rock stability of the layered rock mass roof.

(4) The time has no effect.

(5) It is essential to consider the rock weight of the falling surrounding rock while avoiding too cumbersome analysis. To establish the mathematical model, the load on the upper part of the failing roof is the original rock stress.

(6) Under the layered rock mass, each layer of rock mass parallel to each bedding plane has transversely isotropic and the same composition. Moreover, the interlayer of rock mass perpendicular to the bedding plane has longitudinal anisotropy. 
To facilitate the analysis, the left half part of the arch was taken to establish the mechanical model (Figure 1).

Considering the horizontal stress $T$, the caving arch was cut open from the middle, and the left part was taken for research. The vertical functions were uniformly distributed $\operatorname{load} q$ and lateral uniformly distributed $\operatorname{load} \lambda_{q}$, then the moment equilibrium equation of point $M$ is as follows [25-27]:

$$
T y-\frac{q x^{2}}{2}-\frac{\lambda q y^{2}}{2}=0 .
$$

Regarding the projection equilibrium equation of the whole left half of the force along the $x$-axis direction, we have the following:

$$
T=\lambda q b+\frac{f q a}{K}
$$

It can be obtained as follows:

$$
b=\frac{a}{\lambda} \sqrt{\left(\frac{f}{K}\right)^{2}+\lambda}-\frac{f a}{\lambda K} .
$$

Substituting the above formula into the original formula (1), the mechanical equilibrium equation of the caving arch is obtained as follows:

$$
\frac{x^{2}}{\left(\sqrt{\lambda}(a / \lambda) \sqrt{(f / K)^{2}+\lambda}\right)^{2}}+\frac{\left(y-(a / \lambda) \sqrt{(f / K)^{2}+\lambda}\right)^{2}}{\left((a / \lambda) \sqrt{(f / K)^{2}+\lambda}\right)^{2}}=1,
$$

where $f$ represents the hardness coefficient, $a$ denotes the semiwidth of the roadway, $q$ shows the roof load of the roadway $(\mathrm{MPa}), \lambda$ is the lateral pressure coefficient, and $K$ represents the safety coefficient.

According to the on-site investigations and previous research findings on roadway caving, a caving arch structure was formed from bottom to top by the roof surrounding rock caving gradually until the rock mass at the roof could bear caving under a certain span. Therefore, since the roof surrounding rock of layered surrounding rock body fell gradually from bottom to top, the mechanical model of the surrounding rock caving arch of the roadway roof was correspondingly established (Figure 2).

The surrounding rock of the roadway roof is divided into $n$ horizontal rock layers. The first horizontal layer is the rock layer for the first time caving rock layer with the height of $h_{1}$, and the span is $2 a$ (the roadway width), the effects of the roof surrounding rock horizontally bearing stress on the height of caving arch were calculated based on the model introduced in the literature [28-33]. The morphology and structure of the $2^{\text {nd }}$ caving layer were analyzed based on the first time caving rock layer.

The shape of the caving arch within the range of the first time caving layer is as follows:

$$
\frac{x_{1}^{2}}{\left(\sqrt{\lambda}\left(a_{1} / \lambda\right) \sqrt{\left(f_{1} / K_{1}\right)^{2}+\lambda}\right)^{2}}+\frac{\left(\left(b_{1}-h_{1}\right)-\left(a_{1} / \lambda\right) \sqrt{\left(f_{1} / K_{1}\right)^{2}+\lambda}\right)^{2}}{\left(\left(a_{1} / \lambda\right) \sqrt{\left(f_{1} / K_{1}\right)^{2}+\lambda}\right)^{2}}=1
$$

Then, the expression of $x_{1}$ as the first fracture was obtained as follows:

$$
\left\{x_{1}=\sqrt{\lambda\left(\left(b_{1}-h_{1}\right) \frac{a}{\lambda} \sqrt{\left.\left(\frac{f_{1}}{K_{1}}\right)^{2}+\lambda-\left(b_{1}-h_{1}\right)^{2}\right)}\right.}\right\} .
$$

According to the principle of equation (5), the morphological structure of No. $i$ layer of caving was analyzed considering No. $i-1$ rock layer as the basis. Then, the caving arch morphological form within No. $i$ horizontal rock layer of roadway roof could be deduced:

$$
\frac{x_{i}^{2}}{\left(\sqrt{\lambda}\left(a_{i} / \lambda\right) \sqrt{\left(f_{i} / K_{i}\right)^{2}+\lambda}\right)^{2}}+\frac{\left(y_{i}-\left(a_{i} / \lambda\right) \sqrt{\left(f_{i} / K_{i}\right)^{2}+\lambda}\right)^{2}}{\left(\left(a_{i} / \lambda\right) \sqrt{\left(f_{i} / K_{i}\right)^{2}+\lambda}\right)^{2}}=1 .
$$
follows:

Then, the $x_{i}$ as the $n^{\text {th }}$ fracture can be expressed as

$$
\left\{x_{i}=\sqrt{\lambda\left(\left(b_{i}-h_{i}\right) \frac{a_{i}}{\lambda} \sqrt{\left.\left(\frac{f_{i}}{K_{i}}\right)^{2}+\lambda-\left(b_{i}-h_{i}\right)^{2}\right)}\right.}\right\}
$$

wherein $a_{i}=x_{i-1}$. 


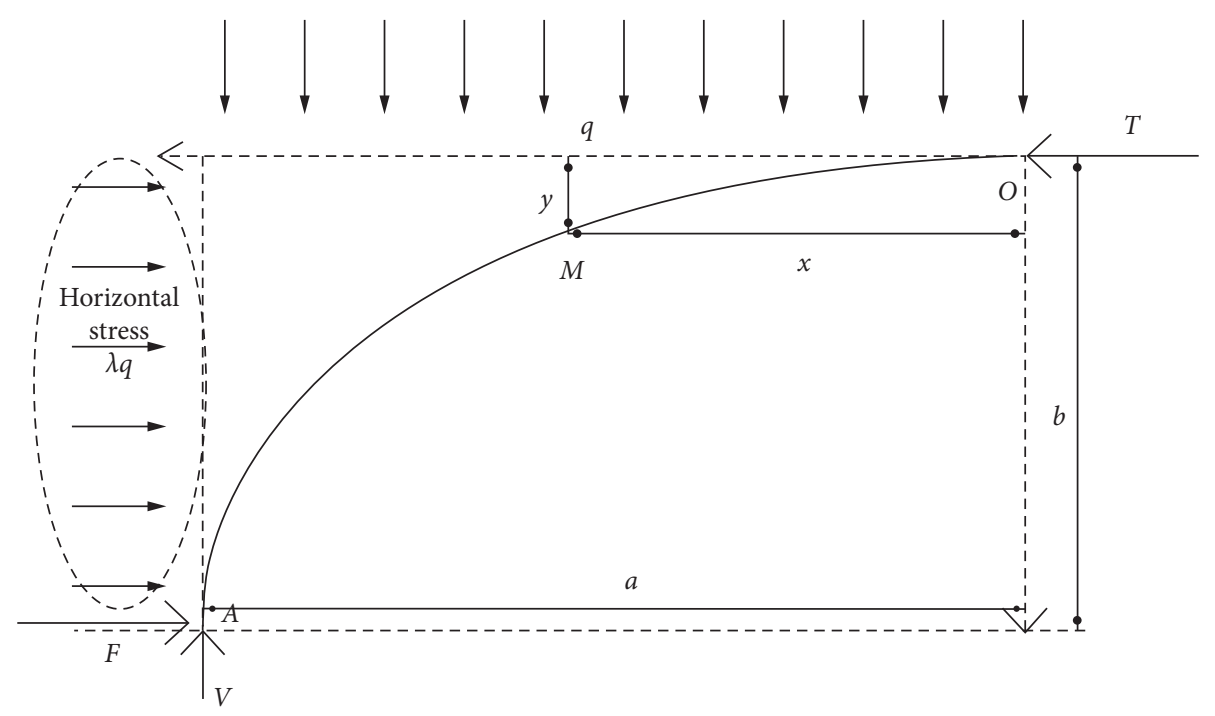

Figure 1: The mechanics model of caving arch.

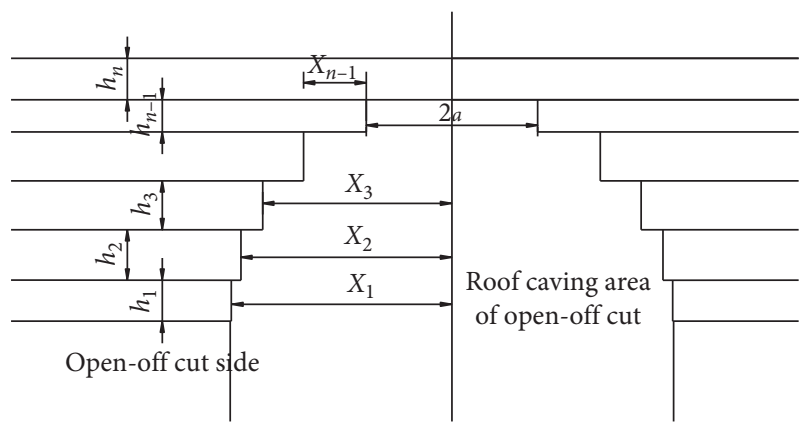

Figure 2: The mechanical model of open-off cut roadway caving arch.

The caving height of the layered rock mass roadway roof is determined by the difference between $b_{i}$ and $h_{i}$ when $b_{i}-h_{i} \leq 0$. The arch structure is in equilibrium with a height of $\sum_{i=1}^{n} b_{i}=h_{1}+h_{2}, \ldots \ldots, h_{i-1}+h_{i}$.

Based on the engineering conditions of 207 working faces of the open-off cut roadway of Wangli No. 1 Mine, the original rock stress load of the roadway was $q=3 \mathrm{MPa}$. The lateral pressure coefficient was $\lambda=1.2$. The roadway width was set as $2 a=8 \mathrm{~m}$, the roadway height was $h=3.5 \mathrm{~m}$, and the stress concentration coefficient was $k=1$. The various rock layers of the roof included the shallow part of $1.4 \mathrm{~m}$ thick composed of fine, silty, and argillaceous sandstone. The Protodyakonov coefficient was $f_{i}=0.3$, and the total thickness of the overlying strata with fine and medium sandstone medium was $13.2 \mathrm{~m}$. Based on the above conditions, it can be calculated as $b_{1}=3.045 \mathrm{~m}, b_{2}=2.572 \mathrm{~m}$, $b_{3}=2.045 \mathrm{~m}, b_{4}=1.395 \mathrm{~m}$, since $b_{4}=1.395 \mathrm{~m} \leq h_{3}=1.4 \mathrm{~m}$, the recursive solution ends. Therefore, the caving arch height of open-off cut roadway roof of 207 working face of layered surrounding rock body should be as follows:

$$
\sum_{i=1}^{n} b_{i}=h_{1}+h_{2}+h_{3}+h_{4}=1.4+1.4+1.4+1.395=5.595 \text {. }
$$

3.2. Mechanical Analysis on Stability of the Open-OffCut with Argillaceous Cemented Sandstone Layered Roof under Anchor Cable Suspension. The composite roof beam structure within the anchorage range of the bolt was considered as the research object. The simply supported beam structure of the composite roof [32, 34-36] was used to construct a mechanical model for analyzing the stability of the cable suspension structure with an argillaceous cemented sandstone roof (Figure 3).

Under vertical and horizontal stress, the deformation equation of the stratified roof beam is as follows:

$$
\frac{\mathrm{d}^{2} w_{m}}{\mathrm{~d} x^{2}}=\frac{M_{m}(x)}{E J}
$$

where $w_{m}$ is the beam deformation deflection ( $m$ ) and $M_{\mathrm{m}}(x)$ denote the moment of the beam with layered roof $(\mathrm{N} \cdot \mathrm{m}) . E$ is the elastic modulus of the composite beam, $E=$ $\sum_{i=1}^{u}\left(E_{i} h_{i}\right) / \sum_{i=1}^{u}\left(h_{i}\right)(\mathrm{GPa})$ and $u$ show the number of rock layers in the beam. $h_{i}$ represents the rock strata thickness from floor to top in the roof, and $i$ the value is set as $1 \sim u$. $E_{i}$ denotes the elastic modulus of rock strata from floor to top in the roof, GPa. J represents the moment of inertia of beam cross-section, $J=b D^{3} / 12\left(\mathrm{~m}^{4}\right)$, and $b$ is the cross-section width of a roof beam $(\mathrm{m})$.

The roof anchorage within the bolt supporting range was deemed as the simply supporting structure of the beam. Based on the mechanical theory of layered roof beam, the moment equation of layered roof beam is as follows:

$$
\begin{aligned}
M_{m}(x)= & -\frac{P_{v} L}{2} x+\frac{P_{v} x^{2}}{2}-P_{h} D w_{m}+M_{F m}(x), \\
M_{F m}(x)= & \sum_{t=1}^{n}\left[\frac{F_{c}}{L}\left(L-\sum_{i=1}^{t}\left(a_{i}\right)\right) x\right]- \\
& \sum_{t=1}^{m}\left[F_{c}\left(x-\sum_{j=1}^{t}\left(a_{j}\right)\right)\right] x \in\left(\sum_{j=1}^{m}\left(a_{j}\right), \sum_{j=1}^{m+1}\left(a_{j}\right)\right),
\end{aligned}
$$




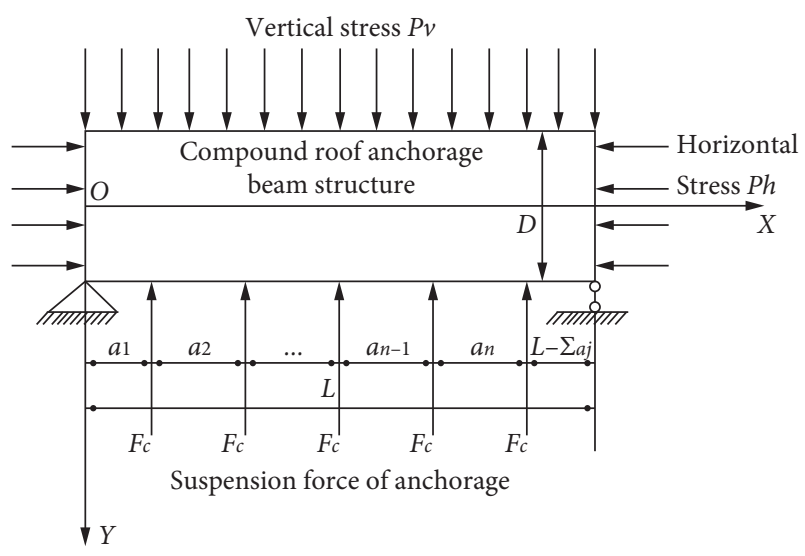

FIgURE 3: The mechanical model schematic diagram of composite beam structure under cable suspension.

where $P_{v}$ is the vertical stress, $\mathrm{MPa}$, and $P_{h}$ show the horizontal stress, MPa. $L$ represents the beam span, m. $D$ is the structural thickness of the roof anchor beam, $\mathrm{m}$, and $M_{F m}(x)$ shows the moment of the cable position in the beam, N.m. $F_{c}$ represents the concentrated force of roof anchor cable suspension, $\mathrm{kN}$, and $n$ is the number of disposing roof cables. $a_{i}$ denotes the space between cables, m. $m$ has the value of $1 \sim n$, representing the position of No. $m$ anchor cable inside the roof, and its distance to the roof end origin is $\sum_{j=1}^{n}\left(a_{j}\right)$.
Letting $k^{2}=\left(P_{h} D / E J\right)$, the general solution of the differential equation is obtained:

$$
\begin{aligned}
w_{m}= & A_{m} \cos (k x)+B_{m} \sin (k x) \\
& +\frac{-P_{v} L x+P_{v} x^{2}-M_{F m}}{E J k^{2}}-\frac{P_{v}}{E J} \\
M_{m}(x)= & -P_{h} D\left[A_{m} \cos (h x)+B_{m} \sin (h x)-\frac{P_{v}}{P_{h} D k^{2}}\right], \\
F s_{m}(x)= & P_{h} D k\left[A_{m} \sin (k x)-B_{m} \cos (k x)\right],
\end{aligned}
$$

where $F s_{m}$ shows the sheer force of beam with layered roof, N. $A_{m}, B_{m}$ are the node coefficients of each cable in the beam structure.

According to the continuity of beam, the deflection, moment, and shear force conditions at each position of the beam are satisfied as follows: $\left.w_{m}(x)\right|_{x=\sum_{j=1}^{m}\left(a_{j}\right)}=$ $\left.w_{m-1}(x)\right|_{x=\sum_{j=1}^{m}\left(a_{j}\right)} ;\left.M_{m}(x)\right|_{x=\sum_{j=1}^{m}\left(a_{j}\right)}=\left.M_{m-1}(x)\right|_{x=\sum_{j=1}^{m}\left(a_{j}\right)}$; $\left.F s_{m}(x)\right|_{x=\sum_{j=1}^{m}\left(a_{j}\right)}=\left.F s_{m-1}(x)\right|_{x=\sum_{j=1}^{m}\left(a_{j}\right)}+F_{c}$.

Meanwhile, at both ends of the roof beam, there are $\left.w_{0}(x)\right|_{x=0}=0,\left.\quad w_{n+1}(x)\right|_{x=L}=0,\left.\quad M_{0}(x)\right|_{x=0}=0, \quad$ and $\left.M_{n+1}(x)\right|_{x=L}=0$.

Integrating the boundary conditions with the formulas (12)-(14), we have the following:

$$
\left\{\begin{array}{l}
A_{0}=\frac{P_{v}}{P_{h} D k^{2}} \\
B_{0}=\frac{P_{v}}{P_{h} D k^{2}}\left(\frac{1}{\sin (k L)}-\cot (k L)\right)+\frac{F_{c}}{P_{h} D k}\left(\sum_{t=1}^{n} \cos \left(k \sum_{j=1}^{t}\left(a_{j}\right)\right)-\cot (k L) \sum_{t=1}^{n} \sin \left(k \sum_{j=1}^{t}\left(a_{j}\right)\right)\right) \\
A_{m}=A_{m-1}+\frac{F_{c}}{P_{h} D k} \sin \left(k \sum_{j=1}^{m}\left(a_{j}\right)\right) \\
B_{m}=B_{m-1}-\frac{F_{c}}{P_{h} D k} \cos \left(k \sum_{j=1}^{m}\left(a_{j}\right)\right)
\end{array}\right.
$$

in which $A_{0}$ and $B_{0}$ are the node coefficients at the beginning end of the beam structure.

\section{Research on Supporting Technology for the Large-Span Open-Off Cut with Argillaceous Cemented Sandstone Layered Roof}

4.1. Support Scheme Design. Based on the on-site investigation and above theoretical analysis and research, the supporting scheme was designed for the surrounding rock of the 31 upper 207 large-span open-off cut roadway of Wanli
No. 1 Mine (Figures 4 and 5). The main supporting parameters and specific supporting scheme are as follows:

(1) Roof supporting parameters: as shown in Figure 4, the roof bolts were made of $\Phi 18 \times 2100 \mathrm{~mm}$ deformed steel bolt, equipped with a $150 \times 150 \times 10 \mathrm{~mm}$ dish-shaped iron tray. The distance between rows is $900 \times 1000 \mathrm{~mm}$; the cables were made of $\Phi 17.8 \times 8000 \mathrm{~mm}$ and $\Phi 17.8 \times 6500 \mathrm{~mm}$ steel strands, equipped with $300 \times 300 \times 16 \mathrm{~mm}$ flat trays. The distance between bolts on both sides of the roadway roof to each roadway side was $250 \mathrm{~mm}$. For 


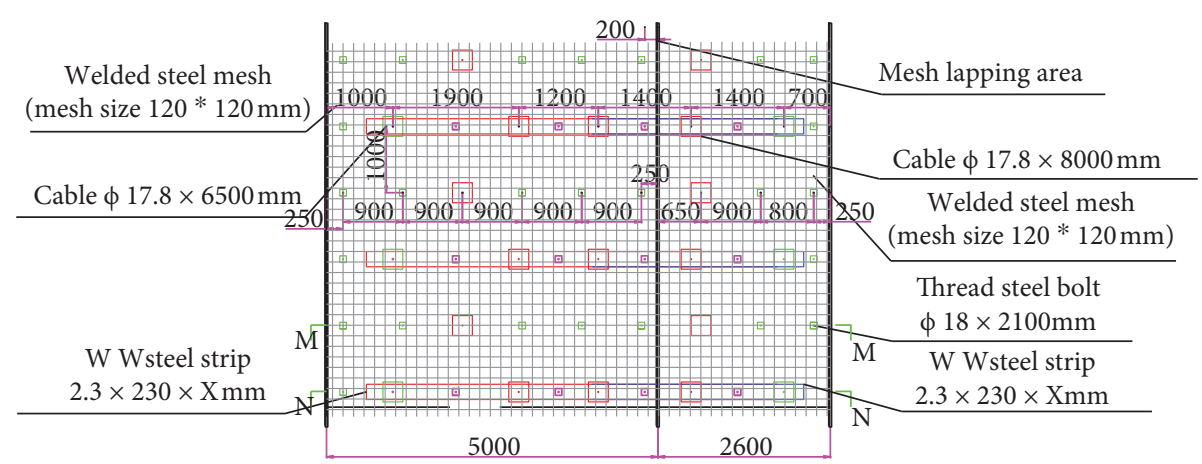

FIgURE 4: The schematic diagram of supporting for 31 upper 207 open-off cut roadway roof.

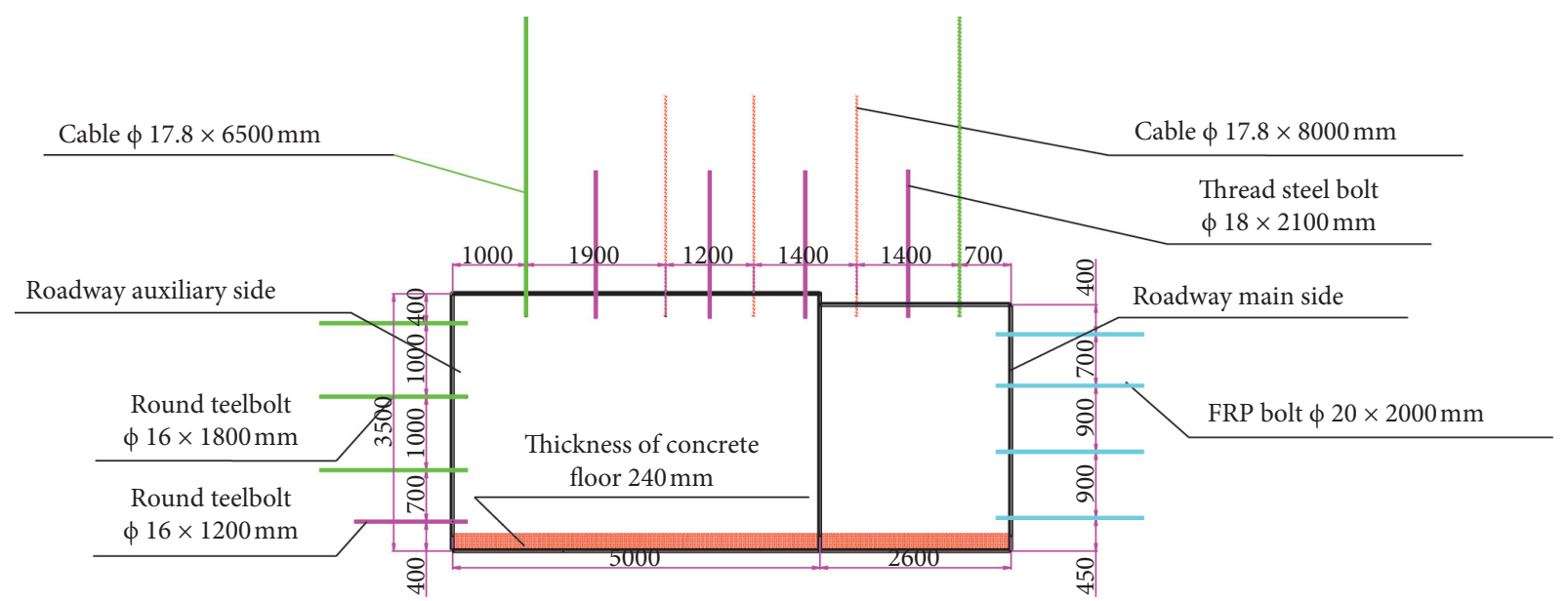

FIGURE 5: The sectional diagram of supporting for 31 upper 207 open-off cut roadway roof.

other bolts, the distance between the main and the auxiliary sides were all $900 \mathrm{~mm}$, and the row spacing of the roof bolt was set as $1000 \mathrm{~mm}$. Five anchor cables were arranged on the roof (including 3 cables in the middle, the spacing of $1200 \times 2000 \mathrm{~mm}$ between rows, and 2 cables were installed on the roof on both sides with $250 \mathrm{~mm}$ spacing to the corresponding side respectively). They were connected by a W-shaped steel strip. Another 2 cables were installed between each row cables with the spacing of $3600 \times 2000 \mathrm{~mm}$ for safety; the reinforcement mesh was welded with $\Phi 6.5 \mathrm{~mm}$ steel bars, the mesh size was $5400 \times 1100 \mathrm{~mm}$, the reinforcement mesh was $120 \times 120 \mathrm{~mm}$. The steel mesh was used horizontally with its long side vertical to both sides of the roadway with the overlapped mesh of $100 \mathrm{~mm}$. The mesh patches were bound by $14^{\#}$ double-strand lead wires into "W" shapes. Moreover, the spacing between binding wires should not be greater than $240 \mathrm{~mm}$. The bolts were applied to compact the overlapped part of mesh patches. For parts that cannot be compacted by bolts, the binding wire should be densified for connection, and the spacing should not be greater than $200 \mathrm{~mm}$.
(2) The parameters of roadway side supporting: as shown in Figure 5, the main side bolts were made of $\Phi 20 \times 2000 \mathrm{~mm}$ FRP with $900 \times 1000 \mathrm{~mm}$ spacing between rows. Each row was supported by 4 bolts, the top row bolts of the roadway side were $400 \mathrm{~mm}$ away from the roof. Meanwhile, the top bolt of each row cooperated with bamboo tray supporting. The side mesh was made of $35000 \times 5000 \mathrm{~mm}$ flame-retardant plastic mesh, and the overlapped part between the plastic mesh patches was no less than $100 \mathrm{~mm}$ and bound by the double-stranded $14^{\#}$ lead wires into a "W"-shape. The distance between binding wires was no more than $200 \mathrm{~mm}$. The auxiliary bolts were made of $\Phi 16 \times 1800 \mathrm{~mm}$ round steel bolts and equipped with a $120 \times 120 \times 8 \mathrm{~mm}$ tray. The spacing between rows was $1000 \times 1000 \mathrm{~mm}$, and the bolts of the top row were $400 \mathrm{~mm}$ away from the roof. The side mesh was made of $2900 \times 1100 \mathrm{~mm}$ reinforcing mesh, for which the overlapped part of the reinforcing mesh patches was about $100 \mathrm{~mm}$. The overlapped part should be bound by double-strand $14^{\#}$ lead wire into a "W"-shape. The spacing between binding wires should not be more than $300 \mathrm{~mm}$, at the same time. The overlapped part width of the 
auxiliary mesh and the roof mesh was no less than $100 \mathrm{~mm}$.

\subsection{Stability Verification of Anchored Roof Supporting}

4.2.1. Stability Mechanics Discrimination. The maximum deflection $w_{\text {Max }}$ of the mechanical model of the Layered roof beam under the action of cables suspension was obtained based on equations (12) and (15). The bearing stability of the cable suspension structure was evaluated considering the rock mass gravity load of the roof caving area by the cable suspension and the roof bending deformation as the standard. Hence, the equation for stability criterion condition of the roof surrounding rock-supporting was obtained:

$$
\begin{aligned}
n F_{c} & >\gamma H_{b} L, \\
w_{\max } & \leq[w],
\end{aligned}
$$

where $n$ is the number of cables, 5 cables were arranged; $\gamma$ shows the bulk density of roof rock mass, for which, the value was adjusted as $2600 \mathrm{~kg} / \mathrm{m}^{3} ; H_{b}$ is the maximum height of roof caving range, the roof caving height of 207 open-off cut was around $4 \mathrm{~m}$ based on the on-site investigation; [ $w]$ is the roof bending deformation, $\mathrm{mm}$. Considering the tensile elongation rate of cable, it is taken as $10 \%$ of cable length of the anchor $l_{m s} ; L$ is the span adjusted as $7.6 \mathrm{~m} ; w_{\max }$ shows the maximum bending deformation of the roof, $\mathrm{mm}$.

Integrating equations (12), (14), and (15), we have the following:

$$
\begin{aligned}
n F_{c} & =5 \times 400 \times 10^{3}=20 \times 10^{5}>\gamma H_{b} L b \\
& =2.6 \times 10^{4} \times 4 \times 7.6 \times 2=15.8 \times 10^{5}, \\
w_{\max } & =194.4 \mathrm{~mm} \leq[w]=7 \% \times 8.0=560 \mathrm{~mm} .
\end{aligned}
$$

The above stability criterion calculation was considered for the surrounding rock-supporting of the open-off cut roadway with argillaceous cemented sandstone rock roof of 207 working face. It was found that the rock mass gravity load was stable in the roof caving area by open-off cut roadway cable suspension of 207 working face. Moreover, the roof bending deformation was within the bearing capacity range of the cable suspension structure. Therefore, the proposed support design scheme met the safety requirements.

4.2.2. Stability Numerical Simulation Analysis. Brief introduction of numerical modeling: FLAC3D modeling is represented in Figure 6 . The lateral four faces adopt a horizontal fixed boundary. A vertical fixed boundary is adopted by the bottom, and the top boundary is set as the stress boundary. The load is $120 \mathrm{~m}$ and the dead weight of the overlying strata is about $3 \mathrm{MPa}$. The rock mechanics test results were obtained by the on-site geological survey and related research. The rock mass mechanics parameters used in the simulation calculation are presented in Table 1.

Simulation process: The parameter modeling and parameter assignment of the surrounding rock conditions were integrated for the cut roadway in the 31 upper 207 working face open-off cut roadway of Wanli No. 1 Coal Mine. The boundary mechanical conditions and displacement conditions are given or limited, and the initial stress field (unexcavated disturbance) balance is completed. First, the stress environment of the surrounding rock of the cut roadway is simulated and calculated in the balanced 31 upper 207 working face open-off cut roadway. The cut roadway in 31 upper 207 working face open-off cut roadway is calculated and balanced; then the displacement is cleared and the cut roadway is excavated to analyze the deformation. Hence, the failure process and evolution law of the surrounding rock of the roadway under the condition of layered rock mass without support are assessed. The simulation calculation of roadway excavation is completed. Thus, the stress state, failure, and deformation characteristics of roadway surrounding rock under the condition of cut roadway layered rock mass in 31 upper 207 working face open-off cut roadway are analyzed.

As seen in Figure 7, the bolt anchorage range covered most plastic areas of the layered roof surrounding rock. Moreover, the plastic area in the deeper region was borne by the cable and steel belt suspension. According to the comprehensive simulation, it was believed that the maximum depth of the plastic area of the layered roof surrounding rock reached $3.5 \mathrm{~m}$. However, there may be local layer separation at $5 \mathrm{~m}$ position. Fortunately, the anchoring position of the cable reached $8 \mathrm{~m}$ depth, guaranteeing a comparatively stable bearing effect.

According to Figure 8, when the yield load of the bolt was $335 \mathrm{MPa}$, the maximum bear load of the bolt was $156 \mathrm{MPa}$, and the same data of cable was $1200 \mathrm{MPa}$. Meanwhile, the maximum force load of the cable was $420 \mathrm{MPa}$. At the same time, the stress deformation of bolt and cable were, respectively, $0.05 \mathrm{~m}$ and $0.9 \mathrm{~m}$. They were both lower than the $18 \%$ and $7 \%$ elongation rate requirements on components of bolt and cable. The roadway supporting structure of the 207 open-off cut roadway layered roof and the control status of surrounding rock were both stable. This indicated that the supporting effect is effective and the surrounding rock deformation was effectively controlled.

\subsection{Feedback and Analysis of Supporting Effects on Engineering Site}

4.3.1. The Feedback Evaluation of Borehole Peering Situation on the Roof Surrounding Rock. Considering the complicated geological conditions of the surrounding rock, it is normally hard to accurately obtain the failure distribution of roadway surrounding rock mass by mechanical theory derivation and analysis. Therefore, the technical means of borehole peering could be utilized to intuitively collect information on the development of surrounding rock failure. Two measuring points were arranged at the appropriate positions of the 207 open-off cut roadway roof.

In the peeping image of $1^{\#}$ borehole, significant failure characteristics could be seen clearly on the roof surface surrounding the rock. There was a broken surrounding rock 


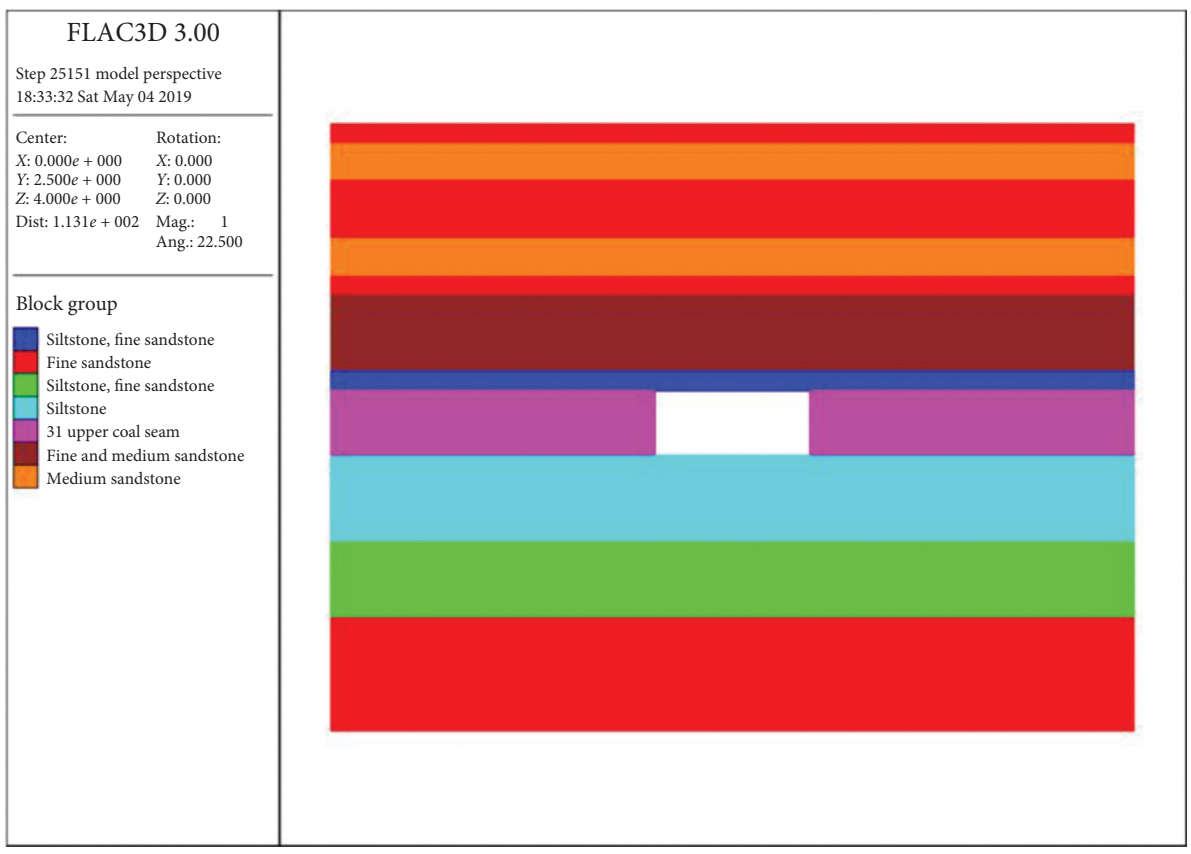

FIGURE 6: The numerical calculation model.

TABLE 1: The mechanical parameters of coal and rock.

\begin{tabular}{|c|c|c|c|c|c|c|}
\hline Mineral & $\begin{array}{l}\text { Bulk density }(\mathrm{kg} / \\
\left.\mathrm{m}^{3}\right)\end{array}$ & $\begin{array}{c}\text { Shear modulus } \\
(\mathrm{GPa})\end{array}$ & $\begin{array}{l}\text { Bulk modulus } \\
(\mathrm{GPa})\end{array}$ & $\begin{array}{c}\text { Cohesion } \\
(\mathrm{MPa})\end{array}$ & $\begin{array}{c}\text { Friction angle } \\
\left({ }^{\circ}\right)\end{array}$ & $\begin{array}{c}\text { Tensile strength } \\
(\mathrm{MPa})\end{array}$ \\
\hline Medium sandstone & 2560 & 0.47 & 0.62 & 1.20 & 28 & 0.50 \\
\hline Fine sandstone & 2600 & 0.46 & 0.61 & 1.10 & 28 & 0.46 \\
\hline $\begin{array}{l}\text { Fine and medium } \\
\text { sandstone }\end{array}$ & 2560 & 0.44 & 0.59 & 1.10 & 27 & 0.45 \\
\hline $\begin{array}{l}\text { Fine, silty and muddy sand } \\
\text { strata }\end{array}$ & 2550 & 0.41 & 0.68 & 1.05 & 27 & 0.43 \\
\hline 31 upper coal seam & 2400 & 0.37 & 0.79 & 0.85 & 26 & 0.34 \\
\hline Siltstone & 2450 & 0.42 & 0.71 & 1.10 & 27 & 0.45 \\
\hline Siltstone, fine sandstone & 2560 & 0.44 & 0.59 & 1.10 & 27 & 0.45 \\
\hline Fine sandstone & 2600 & 0.46 & 0.61 & 1.20 & 28 & 0.50 \\
\hline
\end{tabular}

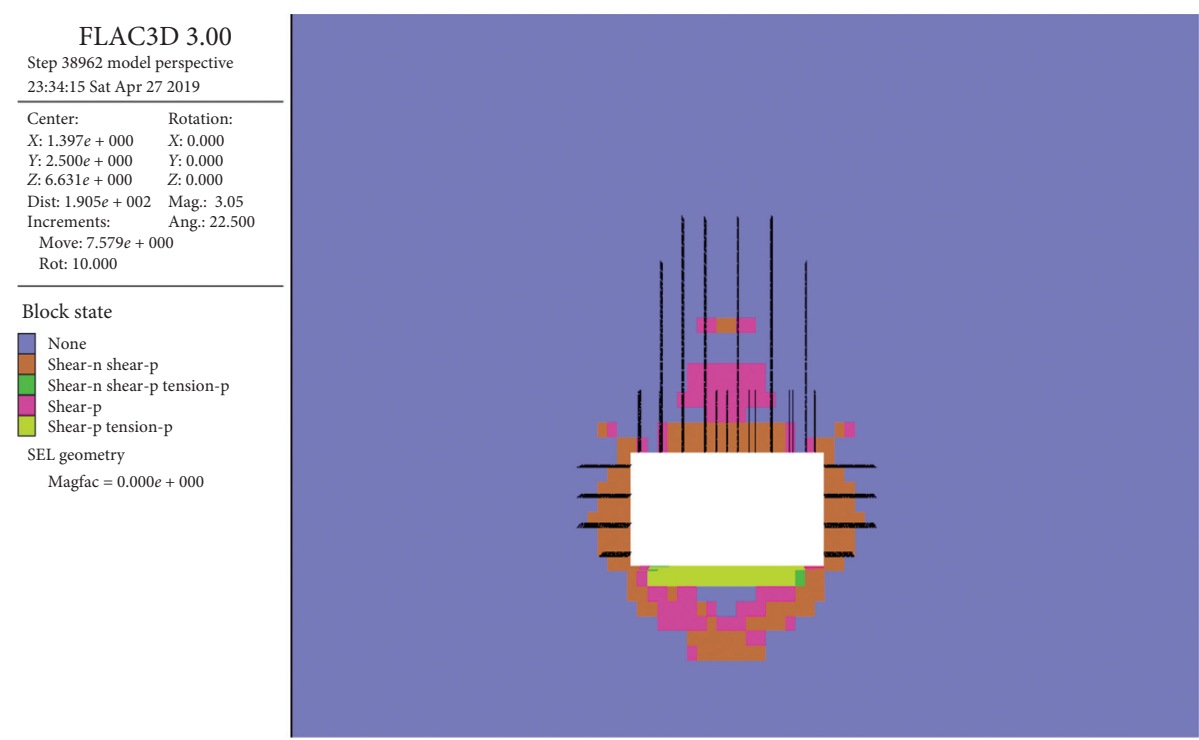

FIGURE 7: The plastic zone distribution of surrounding rock under combined support. 

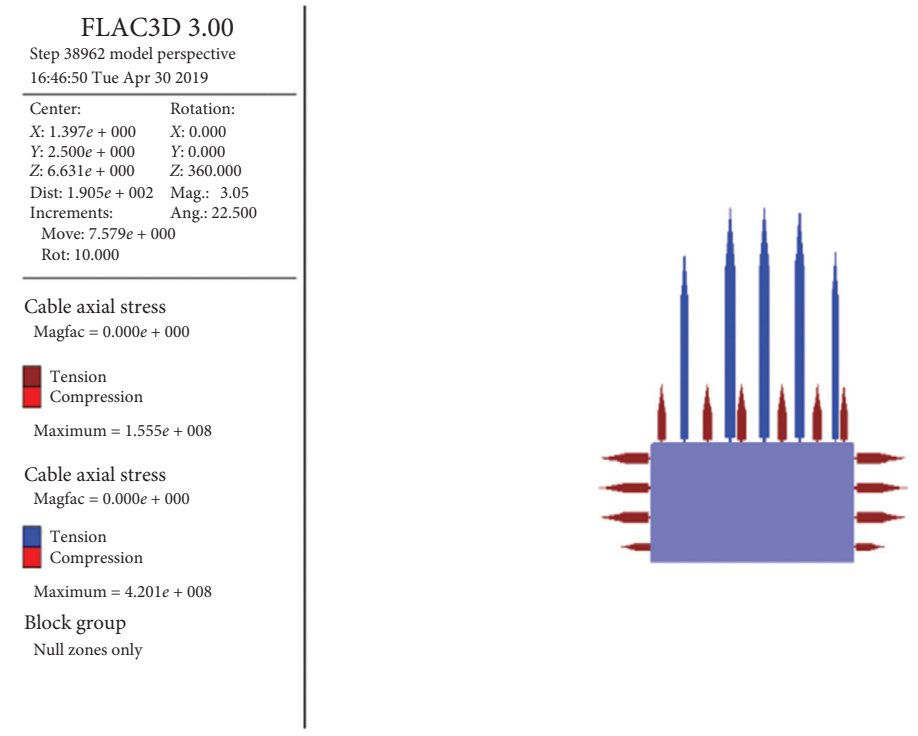

FIgURE 8: The axial stress distribution characteristics of each component under combined support.

attached with silt at $10 \mathrm{~cm}$ depth of $1^{\#}$ borehole. Meanwhile, positions of $150 \mathrm{~cm}, 170 \mathrm{~cm}, 560 \mathrm{~cm}$, and $610 \mathrm{~cm}$ depth of $1^{\#}$ borehole, significant bedding characteristics of rock layer could be observed. No significant cracks were found, although the accumulated water was found in $1^{\#}$ peering lens. It is mainly due to the water spraying and slag discharging measures taken by drilling equipment during the drilling process, which wet the bore wall. Generally, the bore wall of $1^{\#}$ borehole has good integrity, and the roof surrounding rock has no obvious failure characteristics under the support. The deformation and failure status of the surrounding rock at this position are not relatively small.

Obvious surrounding rock fracture characteristics can be observed from the $2^{\#}$ borehole peering image. The bore wall at $20 \mathrm{~cm}$ deep of $2^{\#}$ borehole was comparatively complete. The significant bedding structure characteristics of different rock layer mediums could be seen at $150 \mathrm{~cm}, 220 \mathrm{~cm}, 260 \mathrm{~cm}$, $360 \mathrm{~cm}, 440 \mathrm{~cm}, 500 \mathrm{~cm}$, and $700 \mathrm{~cm}$ depth of $2^{\#}$ borehole. No obvious fractures were found at the above-mentioned positions, though there found obvious bedding structure characteristics of different rock layer medium at $600-800 \mathrm{~cm}$ depth positions of $2^{\#}$ borehole lends. These positions were also within the bolt and cable range. However, no obvious fractures were found there. The cable anchor support function was stable. Based on the integrity bore wall of $2^{\#}$ borehole, the roof surrounding rock had no obvious failure characteristics under the current supporting, and the overall deformation and failure of roadway surrounding rock were small.

4.3.2. The Feedback and Analysis of Supporting Effect on Engineering Site. On the third day after installation, the bearing force of the cable reached stabilized status. The feedback data from the anchor cable dynamometer is represented in Figure 9 based on the observation for nearly $25 \mathrm{~d}$. According to the feedback data, the cable at $1^{\#}$ and $2^{\#}$ measuring points at the middle part of the open-off cut

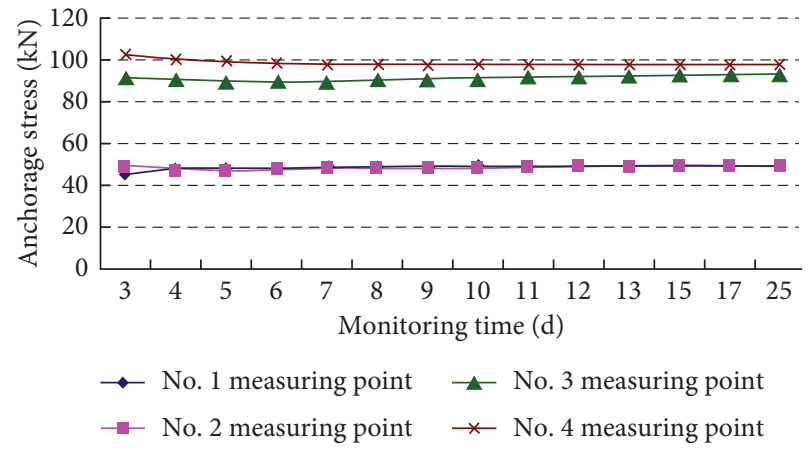

Figure 9: The monitoring feedback of cable stress state.

roadway was borne $45-50 \mathrm{kN}$ pulling force, while the $3^{\#}$ and $4^{\#}$ measuring points at the ends of the open-off cut roadway were borne $90-103 \mathrm{kN}$ pulling force. None of them exceed the limit load of cable. At the same time, the on-site borehole peering was combined to observe the failure and fracture of the roof surrounding rock. It was found that the surrounding rock control of the 207 open-off cut roadway is effective and reaches expected requirements.

\section{Conclusions}

(1) The argillaceous cementation results in poor adhesion between layers of sandstone roof and the low shear strength causes poor loading capacity. These factors simply cause interlayer dislocation and separation. Moreover, the roof also shows obvious bending and deformation owing to the large span of the open-off cut roadway.

(2) Considering the horizontal stratified rock mass as the research object, the mechanical mechanism of the surrounding rock instability and caving of the stratified rock mass roof was assessed. Hence, the 
caving arch height of the open-off cut roadway roof of 207 working faces was obtained.

(3) Taking the composite roof beam structure within the anchorage range of bolt as the research object, the mechanical analysis equation was deduced for the cable suspension stability of composite roof beam by the layered beam mechanical model. Thus, the supporting stability of the open-off cut roadway was analyzed and evaluated.

(4) The bolt anchors support the argillaceous cemented sandstone roof into a whole, restraining the interlayer dislocation. The cable layout can provide reliable support reaction force, reduce the span of the roof anchorage body, enhance the roof anchorage body stability, and improve the deformation effect.

(5) The site engineering practice reveals that the combined active supporting countermeasures proposed in this paper had a good effect on controlling largespan open-off cuts with stratified argillaceous cemented sandstone layered roof and met the safety production requirements.

\section{Data Availability}

All data used to support the study are included within the article.

\section{Conflicts of Interest}

The authors declare that they have no conflicts of interest.

\section{Acknowledgments}

This project was supported by Natural Science Foundation Project of Inner Mongolia Autonomous Region (2019MS05053, 2019MS05042, and 2020LH05018).

\section{References}

[1] Y. Tai, H. C. Xia, X. B. Meng, and T. Y. Kuang, "Failure mechanism of the large-section roadway under mined zones in the ultra-thick coal seam and its control technology," Energy Science and Engineering, vol. 8, no. 4, pp. 999-1014, 2020.

[2] Q. G. Huang and F. Gao, "Large section open-off cut supporting technology of fully mechanized caving mining for carboniferous extra-thick coal seam," Advanced Materials Research, vol. 734-737, pp. 566-569, 2013.

[3] D. Zhang, G. Su, and J. X. Cheng, "Combined support technology of open-off cut for high cutting fully mechanized coal mining face in deep mine," Journal of China Coal Society, vol. 35, no. 11, pp. 1883-1887, 2010.

[4] Y. R. Hu, Y. P. Liu, and L. Z. Shi, "Research on supporting technology for surrounding rock of inclined large-span openoff cut roadway," Geotechnical and Geological Engineering, vol. 38, no. 2, pp. 1873-1884, 2020.

[5] C. Ren, K. Q. Li, and Y. K. Zhang, "Study on surrounding rock stability of long-span coal roadway under influence of mining and support technology optimization," IOP Conference Series: Earth and Environmental, vol. 218, p. 012016, 2019.
[6] C. Li, J. H. Xu, J. Z. Pan, and C. Ma, "Plastic zone distribution laws and its types of surrounding rock in large-span roadway," International Journal of Mining Science and Technology, vol. 22, no. 1, pp. 23-28, 2012.

[7] J. Q. Fu, F. Chao, and J. J. Shi, "Investigation into the deformation of a large span roadway in soft seams and its support technology," Mining Science and Technology, vol. 21, no. 4, pp. 531-535, 2009.

[8] Z. Z. Zhang, M. Deng, X. Y. Wang et al., "Field and numerical investigations on the lower coal seam entry failure analysis under the remnant pillar," Engineering Failure Analysis, vol. 115, p. 104638, 2020.

[9] Y. J. Li, "Support technology of large span open-off cut under compound roof in mining soft coal seam," Coal Geology \& Exploration, vol. 46, no. 4, pp. 147-153, 2009.

[10] M. Z. Zhao, R. S. Yang, and J. Fang, "Stability and control technology for coal roadway of composite roof with thinlayered and argillaceous," Revue des Composites et des Materiaux Avances, vol. 28, no. 2, pp. 239-255, 2018.

[11] Z. Q. Zhang, G. X. Xie, L. Wang, and H. Wang, "Study on surrounding rock deformation failure law and soft rock roadway support with thick composite roof," Journal of Engineering Science and Technology Review, vol. 10, no. 4, pp. 204-212, 2017.

[12] R. S. Yang, Z. F. Li, D. M. Guo, P. Xu, and Z. M. Gao, "Numerical simulation and design optimization of the composite roof roadway support for large section," Applied Mechanics and Materials, vol. 170-173, pp. 3500-3506, 2012.

[13] G. C. Zhang, C. W. Zang, M. Chen et al., "Ground response of entries driven adjacent to a retreating longwall panel," International Journal of Rock Mechanics and Mining Sciences, vol. 138, p. 104630, 2021.

[14] Y. Yu, X. Y. Wang, J. B. Bai et al., "Deformation mechanism and stability control of roadway surrounding rock with compound roof: research and applications," Energies, vol. 13, no. 6, p. 1350, 2020.

[15] W. X. Zheng, Q. W. Bu, and Y. Q. Hu, "Plastic failure analysis of roadway floor surrounding rocks based on unified strength theory," Advances in Civil Engineering, vol. 2018, Article ID 7475698, 10 pages, 2018.

[16] W. X. Zheng, Y. L. Zhao, and Q. W. Bu, “The coupled control of floor heave based on a composite structure consisting of bolts and concrete antiarches," Mathematical Problems in Engineering, vol. 2018, Article ID 3545423, 14 pages, 2018.

[17] W. J. Yu and K. Li, "Deformation mechanism and control technology of surrounding rock in the deep-buried large-span chamber," Geofluids, vol. 2020, Article ID 8881319, 22 pages, 2020.

[18] Y. L. Zhao, L. Y. Zhang, J. Liao et al., "Experimental study of fracture toughness and subcritical crack growth of three rocks under different environments," International Journal of Geomechanics, vol. 20, no. 8, p. 04020128, 2020.

[19] W. H. Guo, Q. L. Chang, X. K. Sun et al., "Instability mechanism and control technology for deep-buried large-span complex roof coal roadway for the prevention of coal pollution," Ekoloji Dergisi, vol. 28, no. 107, pp. 1401-1410, 2019.

[20] W. J. Yu, W. J. Wang, N. Zhang et al., "Study of global deformation and control of a thick, layered compound roof in a deep well," Zhongguo Kuangye Daxue Xuebao/Journal of China University of Mining and Technology, vol. 41, no. 5, pp. 725-732, 2012.

[21] Q. S. Bai and S. H. Tu, "Failure analysis of a large span longwall drift under water-rich roofs and its control techniques," Engineering Failure Analysis, vol. 67, pp. 15-32, 2016.

[22] Q. B. Meng, L. H. Kong, L. J. Han et al., "Stability control technology for deep soft and broken composite roof in coal 
roadway," Meitan Xuebao/Journal of the China Coal Society, vol. 42, no. 10, pp. 2554-2564, 2017.

[23] Y. H. Cheng, F. X. Jiang, and L. H. Kong, "Self-bearing capacity for surrounding rock of composite roof of coal roadways and deformation control in deep high stress mine," in Proceedings of the ICMHPC-2010 International Conference on Mine Hazards Prevention and Control, pp. 415-421, 2010.

[24] W. Y. Ma, "The supporting technology and its application research in large section roadway with fracture surrounding rock," International Journal of Earth Sciences and Engineering, vol. 9, no. 4, pp. 1591-1595, 2016.

[25] D. Z. Kong, Q. Li, N. Wang, and G. Y. Wu, "Analysis on the breaking law of soft and thick roof of fully mechanized topcoal caving face," Geotechnical and Geological Engineering, vol. 38, no. 6, pp. 5941-5953, 2020.

[26] Y. L. Zhao, Y. X. Wang, W. J. Wang, L. Tang, Q. Liu, and G. Cheng, "Modeling of rheological fracture behavior of rock cracks subjected to hydraulic pressure and far field stresses," Theoretical and Applied Fracture Mechanics, vol. 101, pp. 59-66, 2019.

[27] Y. F. Zeng, Y. P. Wu, X. P. Lai, and C. Wei, "Analysis of roof caving instability mechanism of large-section roadway under complex conditions," Caikuang yu Anquan Gongcheng Xuebao/Journal of Mining and Safety Engineering, vol. 26, no. 4, pp. 423-427+432, 2009.

[28] D. F. Zhu, Y. H. Wu, Z. H. Liu et al., "Failure mechanism and safety control strategy for laminated roof of wide-span roadway," Engineering Failure Analysis, vol. 111, no. 4, p. 104489, 2020.

[29] F. Russell, R. Guy, and M. Martin, "Fundamental principles of an effective reinforcing roof bolting strategy in horizontally layered roof strata and areas of potential improvement," International Journal of Mining Science and Technology, vol. 28, no. 1, pp. 67-77, 2018.

[30] A. Rami, W. Gabriel, and S. Sinha, "Understanding roof deformation mechanics and parametric sensitivities of coal mine entries using the discrete element method," International Journal of Mining Science and Technology, vol. 30, no. 1, pp. 123-129, 2020.

[31] Y. L. Zhao, Y. X. Zhang, W. J. Wang, W. Wan, and J. Tang, "Modeling of non-linear rheological behavior of hard rock using triaxial rheological experiment," International Journal of Rock Mechanics and Mining Sciences, vol. 93, pp. 66-75, 2017.

[32] K. Jan and B. Maciej, "Evaluation significance of differences between the geotechnical parameters of the lithological rocks roof layers, above mining excavation," Mining Science, vol. 27, pp. 183-197, 2020.

[33] Y. L. Zhao, L. Y. Zhang, W. J. Wang et al., "Experimental study on shear behavior and a revised shear strength model for infilled rock joints," International Journal of Geomechanics, vol. 20, no. 9, p. 04020141, 2020.

[34] D. Y. Hao, Q. L. Cui, J. He, X. P. Guo, and P. Cheng, "Deformation characteristics and separation monitoring of layered roof roadway supported with bolts and cables," Meitan Xuebao, vol. 42, pp. 43-50, 2017.

[35] Y. L. Zhao, L. Y. Zhang, W. J. Wang, W. Wan, and W. H. Ma, "Separation of elastoviscoplastic strains of rock and a nonlinear creep model," International Journal of Geomechanics, vol. 18, no. 1, p. 04017129, 2018.

[36] S. Q. Niu, S. S. Yang, and X. R. Jia, "Shear instability mechanism and support methods of laminated roof and floor strata in roadway," Meitan Xuebao/Journal of the China Coal Society, vol. 39, pp. 325-331, 2014. 